\title{
No added value for Computer-Assisted surgery to improve femoral component positioning and Patient Reported Outcomes in Hip Resurfacing Arthroplasty; a multi-center randomized controlled trial
}

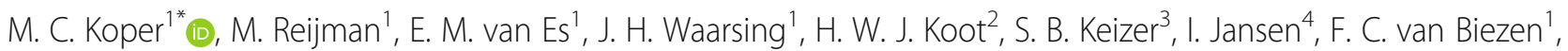
J. A. N. Verhaar ${ }^{1}$ and P. K. Bos ${ }^{1}$

\begin{abstract}
Background: Computer Assisted Surgery (CAS) has proven to improve the accuracy in several orthopedic procedures. Therefore we used this technique to evaluate femoral component positioning in Hip Resurfacing Arthroplasty (HRA). The aim of this study was to evaluate imageless CAS compared to manually implanted femoral components and subsequently evaluates Patient Related Outcome Measures (PROMs). We hypothesized that the use of CAS optimizes the position of the femoral component and improves PROMs.

Methods: This is a multicenter, single-blinded, randomized, controlled trial of two groups. In the CAS group guiding of the femoral component was done with imageless navigation. In the Conventional (control) group the femoral component was placed manually according to the preplanned position. The primary outcome measure consists of a maximum of 3 degrees difference between the postoperative Stem Shaft Angle (SSA) and preplanned SSA. Secondary outcome measures consist of the Hip disability and Osteoarthritis Outcome Scale (HOOS), the Harris Hip Score (HHS) and Visual Analogue Scale (VAS) pain score.

Results: A total of 122 patients were randomized, 61 in the CAS group and 61 in the conventional group. There was no significant differences in accuracy of femoral implant position. The mean difference between the postoperative- and preplanned SSA was -2.26 and -1.75 degrees (more varus) respectively in the CAS and Conventional group. After surgery both groups show significant improvement in all PROMs compared to the baseline measurements, with no significant differences between the groups.
\end{abstract}

Conclusion: Our cohort indicates no benefit for the use of CAS in accuracy of placement of the femoral component in HRA compared to manual implantation. There are no clinical differences in PROMs after 1 year follow up. This study showed no added value and no justification for the use of CAS in femoral component positioning in HRA.

Trial registration: This trial is registered at ClinicalTrails.gov (https://clinicaltrials.gov/) on the 25th of October 2006: NCT00391937.

Level of incidence: Level Ilb, multicenter randomized controlled trial.

\footnotetext{
* Correspondence: maartenkoper@outlook.com

${ }^{1}$ Department of Orthopedics, Erasmus University Medical Center, PO BOX

2040, 3000, CA, Rotterdam, The Netherlands

Full list of author information is available at the end of the article
}

(c) The Author(s). 2019 Open Access This article is distributed under the terms of the Creative Commons Attribution 4.0 International License (http://creativecommons.org/licenses/by/4.0/), which permits unrestricted use, distribution, and reproduction in any medium, provided you give appropriate credit to the original author(s) and the source, provide a link to the Creative Commons license, and indicate if changes were made. The Creative Commons Public Domain Dedication waiver (http://creativecommons.org/publicdomain/zero/1.0/) applies to the data made available in this article, unless otherwise stated. 


\section{Background}

Hip Resurfacing Arthroplasty (HRA) is still considered a viable treatment option for young and active patients with end-stage osteoarthritis of the hip. Initially, this Metal-on-Metal (MoM) articulation showed promising short-term results, with high early return to work rates and high rates of participation in sports activities [1-3]. However, there have been a high number of early failures and a high revision rates [4-8]. This led to a recall of several MoM hip bearings, a more frequent follow-up of patients, and finally to a reduced use of HRA's worldwide. Nevertheless, several HRA's, are still used and reasonable survival rates have been reported. For some implants and patient categories equal to Total Hip Arthroplasty $[9,10]$.

The implantation of a HRA is a challenging procedure, due to reduced visibility and little exposure of the hip joint. A non-optimal placement of the femoral component is related to early femoral neck fractures, loosening, notching and higher risk of impingement with increased wear [11-14]. Therefore, an optimization of positioning of the femoral component in HRA could increase the survival of this bearing and possibly improve Patient Reported Outcomes (PROs).

Computer-Assisted-Surgery (CAS) was introduced to improve the accuracy of component positioning and survival of orthopedic implants. CAS has shown to result in an optimization of implant positioning in total hip arthroplasty [15-17] and an accurate component positioning in HRA's [18-22]. However, there is no clear evidence that CAS improves the femoral positioning in HRA compared to manual placement.

Therefore, in this multi-center, patient-blinded, randomized controlled trail (RCT) we compared femoral component positioning between CAS and manual placement. The primary outcome measure was ability to achieve a postoperative Stem-Shaft Angle (SSA) within 3 degrees of the preplanned SSA. Secondly, we compared different PROMs between the two groups. We hypothesized that CAS results in a more accurate femoral component position and improves PROMs within one-year follow-up.

\section{Methods}

\section{Study design}

All consecutive patients who received an Articular Surface Replacement (ASR) prosthesis (DePuy International Ltd., Leeds, UK) were recruited between October 2006 and January 2010. Patients under the age of 60 (men) and 55 (women) years with nocturnal pain and/or limited walking distance, osteoarthritis (Kellgren Lawrence grade $\geq 2$ ) of the hip, resistant to conservative treatment and eligible for a resurfacing hip prosthesis were asked to participate. Exclusion criteria consisted of a contralateral total hip prosthesis, body mass index $>30 \mathrm{~kg} / \mathrm{m}^{2}$, request to correct an existing leg length discrepancy, not willing to participate in follow-up, proven metal allergy, evident osteoporosis, pathology of the acetabulum (evident acetabular dysplasia: $\mathrm{CE}$ angle of < 15 degrees, hip dysplasia, slipped capital femoral epiphysis and Legg-Calve-Perthes disease), previous hip surgery, vascular deficiency of the lower extremity, renal deficiency, active local or systemic infection, use of steroids and/or immunosuppression, femoral anatomic anomaly, femoral head neck ratio $<1$, and extreme varus position (neck-shaft angle $<110$ degrees). Conservative treated acetabular fractures were not excluded.

Patients were randomized using concealed allocation via a specifically designed website. Stratification took place per orthopaedic surgeon. All patients were blinded for the allocation, whereas the surgeon could not be blinded for the procedure. A standardized anteroposterior (AP) pelvic X-ray was used for calculation of the Centrum-CollumDiaphysis (CCD)-angle and for preplanning of the femoral component. The software used for the preplanning was OrthoView (OrthoView, Meridian Technique Limited, Southampton, United Kingdom). Power analysis calculated a minimal of 117 patients per group in order to show a mean absolute difference of minimally 3 degrees between the postoperative SSA and preplanned SSA (oneside testing alpha $=0.05$ and beta $=0.80$ ). This sample size calculation is based on the study of Beaule et al., were they investigated the relation between the orientation of the femoral component and outcome of an ASR prosthesis [12]. With a follow-up period of three years, a $20 \%$ dropout was calculated and an inclusion of a total of 280 patients (140 each group) needed.

\section{Surgical planning and technique}

Eleven experienced orthopedic hip replacement surgeons were trained to use the CAS-system. They attended an obligatory hands-on instructional cadaver course and a saw bone training. All operations were performed using a standard posterolateral approach. In the CAS group, surgical guiding of the femoral component was done with BrainLab $\mathrm{Ci}^{\text {rs }}$ ASR System 1.0 (BrainLAB AG, Feldkirchen, Germany). There was no additional dissection necessary for CAS compared to the standard hip resurfacing surgery. Both groups received identical antibiotic prophylaxis with Cephalosporin $(1000 \mathrm{mg})$ direct preoperatively and 24-h postoperatively. Thrombosis prophylaxis with Nadroparine was given until 6 weeks postoperatively. A standardized pain medication protocol was used postoperatively. Patients were rehabilitated under the guidance of the physiotherapist with immediate unrestricted weight bearing.

\section{Radiological evaluation}

To calculate the CCD-angle, the preoperative standardized AP-pelvic X-ray was analyzed in a blinded manner 
by two of the authors (MCK, EvE) using GeoGebra (International GeoGebra Institute and GeoGebra $\mathrm{GmbH}$, freeware). Figure 1a demonstrates the use of GeoGebra where multiple marks are placed on the collum and the shaft to calculate the CCD angle. The SSA, defined as the angle between the stem of the femoral HR component and the axis of the femoral diaphysis in the AP projection, was measured on the preplanned AP-pelvic $\mathrm{X}$-ray and direct postoperative AP-pelvic X-ray (Fig. 1b).

\section{Clinical evaluation}

The Hip disability and Osteoarthritis Outcome Scale (HOOS), the Visual-Analogue-Scale (VAS) pain score and the Harris-Hip-Score (HHS) were used to evaluate relevant patient-centered outcomes.

The HOOS is subcategorized in five domains; pain, symptoms, function in daily life, sports and hip related quality of life. Scores on the HOOS range from 0 to 100 , where 0 indicates the worst possible outcome and 100 the best possible [23]. The VAS pain is a validated tool to evaluate pain perception of a patient, and scores range from 0 to 10 , with 0 indicating no pain an 10 being the worst pain experienced [24]. At each outpatient visit the HHS was completed by the orthopedic surgeon and used to score the hip function [25]. The survey has 10 questions and score a range from 0 to 100 with higher scores represent less dysfunction and better outcome.

\section{Data collection}

Surgical blood loss and surgery duration were logged by the anesthesiologist and written on the surgery evaluation form. Each adverse event was classified as 'surgical' when it occurred in the operation room, as 'early' when it occurred within three months after surgery, and as 'late' when it occurred more than three months postoperatively. At the end of the trial, all hospital records of the participating patients were retrieved and checked to verify the adverse events and their extensiveness.

Baseline questionnaires were administered before surgery, and subsequently at 6 weeks, 3 and 12 months postoperative. At each outpatient visit, the HHS was completed by the orthopedic surgeon. The other questionnaires were patient-reported and were sent out electronically (web-based or via email) or sent on paper by post.

\section{Statistical analysis}

Descriptive statistics including means, standard deviations, frequencies and percentages were used to describe the patient characteristics. For all X-ray measurements the intra-observer and inter-observer reliability were evaluated using the intra-class correlation coefficient (ICC). We used a two-way mixed model with absolute agreement and a confidence interval of $95 \%$. The ICC values range from 0 to 1 , in which 1 indicates perfect reliability and an ICC greater than 0.75 considered acceptable [26].

Intention-to-treat analyses were used for all variables. However, due to some protocol violations, all data were also analyzed per protocol. The independent $\mathrm{t}$-test was used to assess differences between groups for continuous

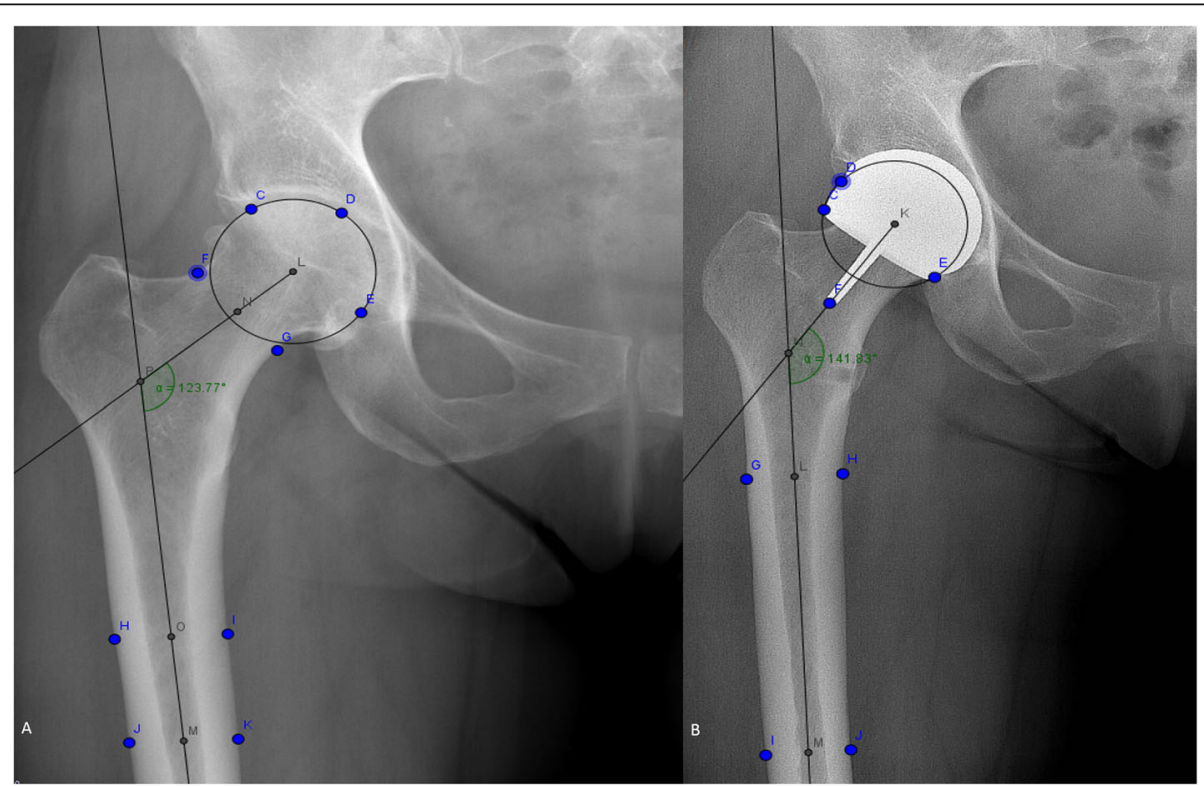

Fig. 1 Examples of the use of GeoGebra (International GeoGebra Institute and GeoGebra GmbH, freeware) to calculate the Center-CollumDiaphysis (a) and the postoperative Stem-Shaft-Angle (b) 
data, while the Chi-square test was used to assess differences in categorical data. To assess differences in continuous data over time within the same treatment group, a paired t-test was used. For the implant survival analysis, a Kaplan-Meier was used to compare treatment groups. Events were defined as revisions of the femoral and/or acetabular component for any reason, and patients without an event were censored at 3 year postoperative. All analyses were performed using SPSS 20(IBM Corporation, Armonk, NY). All tests were two-sided and a $p$-value $<0.05$ was considered significant.

\section{Results}

During the trial period, a total of 125 patients (133 hips) were included, 67 hips were randomized to the conventional group and 66 hips to the CAS group. The study flowchart is depicted in Fig. 2 and patient characteristics in Table 1. A total of 11 randomized patients were excluded due to primary missing data and loss of follow up, five patients in the conventional group and six patients in the CAS group. These patients showed no difference in baseline characteristics. In general, patients in both groups were similar, except for BMI, which was significantly higher in the CAS group (26.9 versus 25.5 , $p=0.003$ ), which can be explained by a higher body weight (Table 1). Unfortunately, due to an international recall of the ASR prosthesis after publications of high complication and failure rates the study was prematurely ended. This resulted in a lower number of inclusions needed and incompleteness of data gathered by the participated orthopedic surgeons.

\section{Surgical details}

Table 2 shows the details on the surgical procedure for each group. The mean operation time in the CAS group was $\operatorname{significantly}(p<0.001)$ longer, i.e. $19 \mathrm{~min}$. Three minor 'early' adverse events were reported, all in the conventional group. One patient had minor cardiac ischemia, the second patient complained of a painful lower leg and swelling, but thrombosis was excluded. The third patient had a superficial skin infection and required oral antibiotics. All resolved without further problems.

Protocol violations occurred thirteen times. Ten of the CAS randomized patients were operated without CAS due to no CAS system availability during surgery. Two

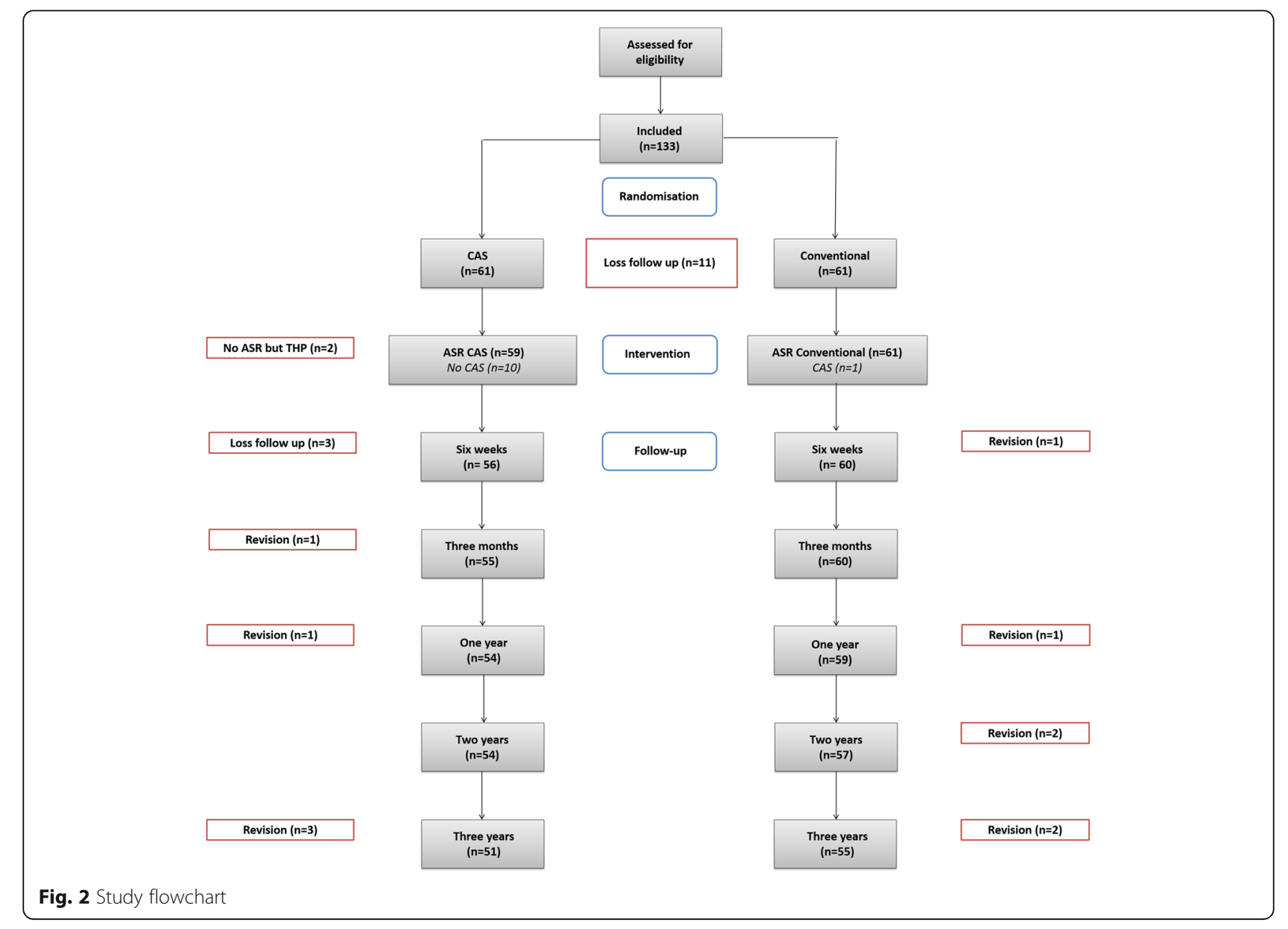


Table 1 Baseline patient characteristics for the CAS and Conventional group

\begin{tabular}{lllll}
\hline & CAS $(n=61)$ & Conventional $(n=61)$ & $P$-value & Excluded hips $(n=11)$ \\
\hline Age (years) (SD: range) & $50(6.3: 22$ to 60$)$ & $50(6.4: 29$ to 60) & 0.887 & $45.64(6.9: 37-59)$ \\
Weight (kg) (SD: range) & $85.6(11.3: 62-107)$ & $79.7(12.27: 53-110)$ & $0.006^{*}$ & $77.9(11.5: 55-95)$ \\
Length (cm) (SD: range) & $178.3(8.9: 161-196)$ & $176.2(9.2: 157-196)$ & 0.210 & $175.2(10.5: 164-197)$ \\
BMI (kg/m²) (SD: range) & $26.9(2.6: 20.3$ to 30.1$)$ & $25.5(2.4: 20.4-29.4)$ & $0.003^{*}$ & $25.3(2.9: 19.0-29.8)$ \\
Gender (Men: Women) & $39: 22$ & $42: 19$ & 0.702 & $6: 5$ \\
Side (L: R) & $25: 36$ & $29: 32$ & 0.585 & $7: 3$ \\
\hline
\end{tabular}

CAS Computer-Assisted-Surgery, BMI Body Mass Index

Age, Weight, Length and BMI are presented as means. Gender and Side are given as a ratio

patients in the CAS group were excluded because safe femoral component placement was considered not possible and a total hip prosthesis was implanted. One conventional randomized patient was operated with CAS.

\section{Radiographic evaluation}

The intra-observer reliability for the two readers was excellent: $0.98,95 \%$ CI $0.94-0.996$ for reader 1 , and 0.96 , 95\% CI $0.91-0.99$ for reader 2 . The ICC for the interobserver reliability was $0.95,95 \%$ CI $0.89-0.99$. The mean native CCD-angle was 129 degrees in both groups, with no significant difference between the groups. We did find a significant difference $(P=0.033)$ in the preplanned SSA within the intention to treat analysis. This is a baseline difference and we do not have a clear explanation for this and believe this is not of any clinical relevance for the outcome of this study. The mean postoperative SSA minus the preplanned SSA showed no significant difference between the two groups $(p=$ 0.636 ). A slightly more varus position was found in both groups with -2.26 and -1.75 degrees deviation respectively in the CAS and conventional group. Analysis of patients with more than 3 degrees, 7 degrees or 10 degrees

Table 2 Surgery details of the CAS and Conventional groups

\begin{tabular}{llll}
\hline & CAS ( $\mathrm{n}=61)$ & $\begin{array}{l}\text { Conventional } \\
(n=61)\end{array}$ & $P$-value \\
\hline $\begin{array}{l}\text { Surgery time (min) } \\
\text { (SD: range) }\end{array}$ & $116(30: 65-240)$ & $97(24: 60-180)$ & $0.000^{*}$ \\
$\begin{array}{l}\text { Blood loss (mL) } \\
\text { (SD: range) }\end{array}$ & $645(276: 200-1500)$ & $573(282: 150-1500)$ & 0.171 \\
$\begin{array}{l}\text { Component size } \\
\text { (mm) (SD: range) }\end{array}$ & $49(3: 43-57)$ & $49(3: 41-57)$ & 0.635 \\
$\begin{array}{l}\text { CAS protocol } \\
\text { deviations }\end{array}$ & 12 & 1 & \\
- Conventional & 10 & & \\
/CAS & & 1 & \\
- Total Hip & 2 & 0 & \\
Prosthesis & & & \\
\hline
\end{tabular}

CAS Computer-Assisted-Surgery

Surgery time, Blood loss and Component size are given as means. CAS protocol deviations are given as counts

* Significant difference between CAS and Conventional group, $P<0.000$ deviation also showed no significant difference. Table 3 shows all measured data calculated as intention to treat, as well as calculations per protocol.

\section{Clinical evaluation}

Compliance rates for the different questionnaires ranged between 87 and $100 \%$ at baseline, $70-90 \%$ after 6 weeks, $70-90 \%$ after 3 months and $67-90 \%$ after 12 months of follow-up. Reasons for missing data are the international recall of the prosthesis and shutdown of the study website. Table 4 describes all results of the questionnaires during the one year follow-up visits, separately for the two groups.

The baseline mean VAS score in both groups decreased significantly $(P=0.000)$ after 6 weeks of surgery. Between both groups no significant difference at any time point was observed. The HOOS questionnaire at baseline showed no differences between the CAS and conventional group in pain, hip-related quality of life and other symptoms. The conventional group showed significant higher scores in the subscales activities of daily $\operatorname{living}(P=0.028)$ and $\operatorname{sport}(P=0.021)$ at baseline. After 6 weeks, 3 months and one year follow up, no significant differences between the two groups were observed.

The mean HHS was significantly increased in both groups after six weeks $(P=0.000)$, three months $(P=$ $0.000)$ and 1 year $(P=0.026)$ of surgery.

\section{Survival analysis}

During a three-year follow-up period, 11 revisions were performed. An overall survival of $91 \%$ in three years was calculated in the entire group. Table 5 shows the revision characteristic between the two groups. All late events in our clinics were managed with a conventional total hip arthroplasty. With per protocol analysis we found more revisions in the conventional group versus the CAS group (8 versus 3 ) in the three-year follow-up period, this difference was not significant. Figure 3 shows the Kaplan-Meier survival curve between the two groups. 
Table 3 Radiographic evaluation of the angles

\begin{tabular}{|c|c|c|c|c|c|c|}
\hline & \multicolumn{3}{|c|}{$\begin{array}{l}\text { Radiographic evaluation angles (shown as intention to } \\
\text { treat) }\end{array}$} & \multicolumn{3}{|c|}{ Radiographic evaluation angles (shown per protocol) } \\
\hline & CAS $(n=61)$ & $\begin{array}{l}\text { Conventional } \\
(n=61)\end{array}$ & $\begin{array}{l}P \\
\text { Value }\end{array}$ & CAS $(n=50)$ & $\begin{array}{l}\text { Conventional } \\
(n=70)\end{array}$ & $P$ Value \\
\hline $\begin{array}{l}\text { CCD-Angle, degrees } \\
\text { (SD: range) }\end{array}$ & $129,5(6.1: 117-143)$ & $128,6(6.5: 115-149)$ & 0.443 & 129,2 (6.1: 117-143) & $128,9(6.5: 115-149)$ & 0.780 \\
\hline $\begin{array}{l}\text { Preplanned SSA, degrees } \\
\text { (SD: range) }\end{array}$ & 138,3 (3.8: 128-148) & 136,6 (4,8: 127-152) & $0.033^{*}$ & 138,0 (3.8: 128-148) & $137,1(4,7: 127-152)$ & 0.281 \\
\hline $\begin{array}{l}\text { Post-operative SSA, degrees } \\
\text { (SD: range) }\end{array}$ & $136,0(5.7: 124-150)$ & $134,9(6,7: 119-153)$ & 0.311 & 136,3 (5.6: 124-150) & 134,8 (6,6: 119-153) & 0.196 \\
\hline \multicolumn{7}{|l|}{$\begin{array}{l}\text { Difference postoperative } \\
\text { SSA minus preplanned SSA }\end{array}$} \\
\hline $\begin{array}{l}\text { - Mean, degrees } \\
\text { (SD: range) }\end{array}$ & $\begin{array}{l}-2.26(5.8:-15.25- \\
12.11)\end{array}$ & $\begin{array}{l}-1.75(5.9:-13.14- \\
16.21)\end{array}$ & 0.636 & $\begin{array}{l}-1.7(5.9:-15.25- \\
12.11)\end{array}$ & $\begin{array}{l}-2.2(5.8:-13.14- \\
16.21)\end{array}$ & 0.592 \\
\hline $\begin{array}{l}\text { - Absolute, degrees } \\
\text { (SD: range) }\end{array}$ & $5.14(3.5: 0.07-15.25)$ & 4.94 (3.5: 0.04-16.21) & 0.768 & $5.0(3.5)$ & $5.0(3.5)$ & 0.932 \\
\hline - > 3 degrees, n (\%) & $44(72 \%)$ & $40(66 \%)$ & 0.558 & $35(70 \%)$ & $44(61 \%)$ & 0.692 \\
\hline - > 7 degrees, n (\%) & $18(29 \%)$ & $19(31 \%)$ & 0.884 & $12(24 \%)$ & $20(28 \%)$ & 0.534 \\
\hline - > 10 degrees, $n(\%)$ & $6(10 \%)$ & $4(7 \%)$ & 0.517 & $05(10 \%)$ & $10(14 \%)$ & 0.586 \\
\hline
\end{tabular}

$\mathrm{CAS}=$ Computer-Assisted-Surgery, $\mathrm{CCD}=$ Centrum-Collum-Diaphysis, SSA = Stem-Shaft-Angle. ${ }^{*}$ significant difference

\section{Discussion}

In this multi-center, patient-blinded, randomized controlled study we compared imageless CAS versus manual placement of the femoral component in HRA. The primary endpoint of this study was an accurate placement of the femoral component within 3 degrees difference between the postoperative SSA and preplanned SSA. We did not find a difference in accuracy between the CAS and conventional group.

An accurate positioning of the femoral component in HRAs remains a critical step during surgery. A nonoptimal placement of the femoral component is related to early failure. An excessive valgus position results is an increased risk of femoral notching and weakening of the bone with possible avascular necrosis, while a varus position leads to increased femoral neck fractures and aseptic loosening [11, 13, 14, 27, 28]. Increased metal ion levels, adverse reaction to metal debris (ARMD) and pseudotumor formation also seem related to a suboptimal position of components, which may result in increased revision rates $[5,29,30]$. The importance of CAS in component placement in HRA is already shown in preclinical and clinical studies [18, 31-36]. However, most of these clinical studies retrospectively evaluated case series. In this RCT the CCD-angle, preplanned SSA and postoperative SSA were all determined with high intra- and interobserver reproducibility, showing the accuracy of our measurements. The CCD angle in our study was similar for the two treatment groups. We only found a small but significant difference in the preplanned SSA $(P=0.003)$ between the two groups; 138 degrees in the CAS group compared to 137 degrees in

Table 4 Patient Reported Outcomes with one year follow up. Calculated per protocol

\begin{tabular}{|c|c|c|c|c|c|c|c|c|c|c|}
\hline & & \multicolumn{2}{|l|}{ Baseline } & \multicolumn{2}{|l|}{ Six weeks } & \multicolumn{2}{|c|}{ Three months } & \multicolumn{2}{|l|}{ One year } & \multirow{2}{*}{$\begin{array}{l}\text { P-value } \\
\text { (LMM) }\end{array}$} \\
\hline & & CAS & Conventional & CAS & Conventional & CAS & Conventional & CAS & Conventional & \\
\hline VAS & & $5.7(1.9)$ & $5.4(2.0)$ & $1.3(2.0)$ & $1.3(1.8)$ & $0.8(1.3)$ & $0.8(1.3)$ & $0.4(1.0)$ & $0.5(1.2)$ & 0.688 \\
\hline \multirow[t]{5}{*}{ HOOS } & Pain & $38.4(13.0)$ & $40.5(15.4)$ & $81.1(15.5)$ & $79.2(13.3)$ & $87.0(15.6)$ & $86.5(14.7)$ & $91.1(11.2)$ & $88.0(16.7)$ & 0.432 \\
\hline & Other symptoms & $35.0(14.4)$ & $35.7(14.2)$ & $67.2(16.7)$ & $69.0(15.5)$ & $72.5(16.1)$ & $72.2(16.1)$ & 74.5 (18.0) & 75.9 (19.6) & 0.914 \\
\hline & $\begin{array}{l}\text { Activities of daily } \\
\text { living }\end{array}$ & $38.2(14.9) *$ & $42.7(16.4) *$ & $72.8(17.3)$ & $71.2(13.5)$ & $83.2(17.6)$ & $82.2(15.2)$ & $89.6(11.7)$ & $87.3(16.3)$ & 0.333 \\
\hline & Sport & $\begin{array}{l}16.6(14.0) \\
* *\end{array}$ & $22.8(18.3)^{* *}$ & $53.6(29.2)$ & $46.2(25.6)$ & $69.9(26.0)$ & $65.8(25.6)$ & $73.8(24.2)$ & $76.6(23.2)$ & 0.444 \\
\hline & Hip-related QoL & $21.7(12.3)$ & $24.5(11.7)$ & $51.9(16.1)$ & $48.4(16.7)$ & $66.5(20.2)$ & $59.6(17.9)$ & 71.9 (14.6) & $69.0(20.9)$ & 0.309 \\
\hline $\mathrm{HHS}$ & Total & $57.1(10.6)$ & 60.6 (10.6) & 79.1 (16.6) & $80.2(11.5)$ & $91.0(12.8)$ & 93.7 (8.7) & $96.3(7.1)$ & $97.8(4.0)$ & 0.537 \\
\hline
\end{tabular}

CAS Computer-Assisted-Surgery, LMM linear mixed-model, VAS visual analogue scale. HOOS=Hip disability and Osteoarthritis Outcome Scale (HOOS). HHS=Harris Hip Score. All data are presented as means (SD). ${ }^{*}$ significant difference $(p=0.028) .{ }^{* *}$ significant difference $(p=0.021)$ 
Table 5 Revision characteristics for the CAS and Conventional group

\begin{tabular}{|c|c|c|c|c|c|c|c|c|}
\hline & Age/Gender & $\begin{array}{l}\text { Size } \\
\text { component } \\
(\mathrm{mm})\end{array}$ & Revision indication & $\begin{array}{l}\text { Time to revision } \\
\text { (months) }\end{array}$ & $\begin{array}{l}\text { Component } \\
\text { revised }\end{array}$ & $\begin{array}{l}\text { Anatomy } \\
\text { (degrees) }\end{array}$ & $\begin{array}{l}\text { Angle planned } \\
\text { (degrees) }\end{array}$ & $\begin{array}{l}\text { Angle post } \\
\text { (degrees) }\end{array}$ \\
\hline \multirow[t]{5}{*}{ CAS randomized } & 46/Female & 46 & Collum fracture & 3 & Femur & $\begin{array}{l}\text { Normal } \\
(128)\end{array}$ & 133 & 124 \\
\hline & 56/Male & 49 & Collum fracture & 25 & Femur & $\begin{array}{l}\text { Coxa Valga } \\
(136)\end{array}$ & 142 & 135 \\
\hline & 51/Male & 53 & $\begin{array}{l}\text { ARMD, high } \\
\text { cobalt/chromium }\end{array}$ & 29 & $\begin{array}{l}\text { Femur }+ \\
\text { Acetabulum }\end{array}$ & $\begin{array}{l}\text { Normal } \\
(130)\end{array}$ & 136 & 142 \\
\hline & $\begin{array}{l}\text { 54/Female } \\
\text { (no CAS) }\end{array}$ & 47 & Aseptic loosening & 30 & $\begin{array}{l}\text { Femur }+ \\
\text { Acetabulum }\end{array}$ & $\begin{array}{l}\text { Normal } \\
(129)\end{array}$ & 134 & 131 \\
\hline & $\begin{array}{l}\text { 53/Female } \\
\text { (no CAS) }\end{array}$ & 46 & Collum fracture & 1,5 & Femur & $\begin{array}{l}\text { Coxa Valga } \\
(141)\end{array}$ & 143 & - \\
\hline \multirow[t]{6}{*}{$\begin{array}{l}\text { Conventional } \\
\text { randomized }\end{array}$} & 52/Male & 49 & Pain & 25 & Femur & $\begin{array}{l}\text { Normal } \\
(122)\end{array}$ & 137 & 133 \\
\hline & 55/Female & 45 & Aseptic loosening & 8 & $\begin{array}{l}\text { Femur }+ \\
\text { acetabulum }\end{array}$ & $\begin{array}{l}\text { Normal } \\
(127)\end{array}$ & 133 & 141 \\
\hline & 53/Female & 43 & Aseptic loosening & 21 & $\begin{array}{l}\text { Femur }+ \\
\text { Acetabulum }\end{array}$ & $\begin{array}{l}\text { Normal } \\
(126)\end{array}$ & 136 & 140 \\
\hline & 59/Male & 51 & $\begin{array}{l}\text { Pain, high cobalt/ } \\
\text { chromium }\end{array}$ & 23 & $\begin{array}{l}\text { Femur }+ \\
\text { Acetabulu }\end{array}$ & $\begin{array}{l}\text { Normal } \\
(127)\end{array}$ & 138 & 136 \\
\hline & 54/Female & 41 & ALTR & 22 & $\begin{array}{l}\text { Femur }+ \\
\text { Acetabulum }\end{array}$ & $\begin{array}{l}\text { Coxa Valga } \\
(135)\end{array}$ & 132 & 149 \\
\hline & 48/Male & 51 & Aseptic loosening & 0.5 & Acetabulum & $\begin{array}{l}\text { Normal } \\
(134)\end{array}$ & 138 & 134 \\
\hline
\end{tabular}

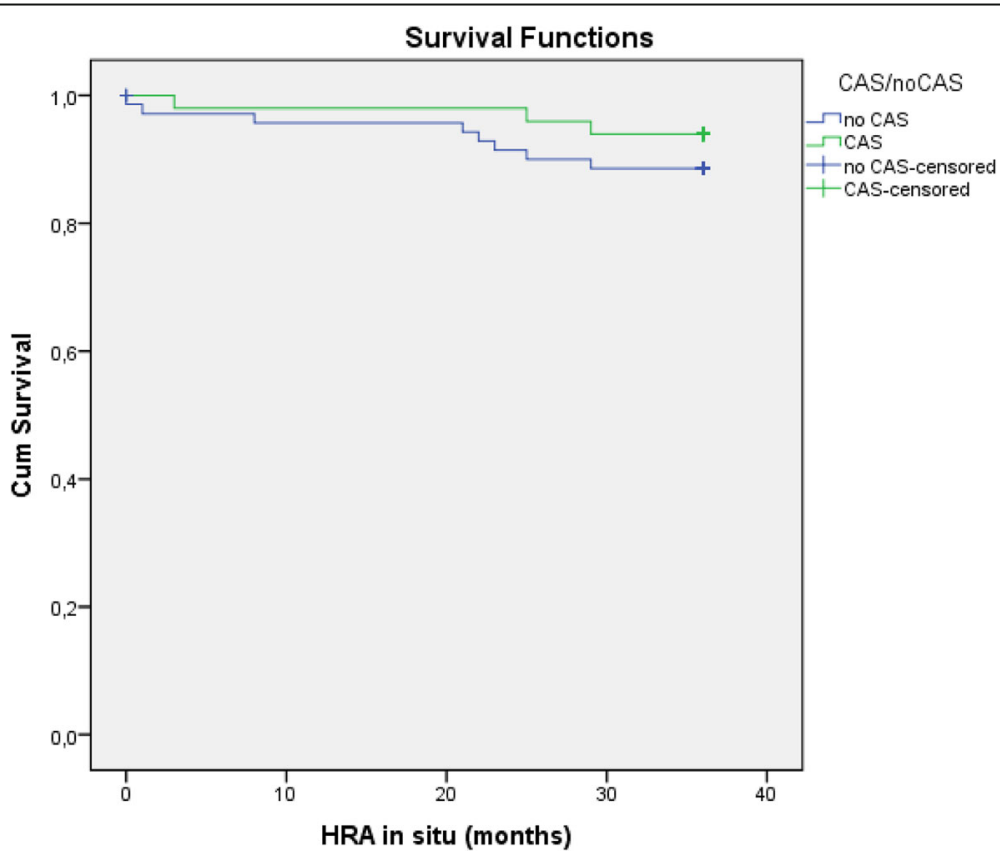

Fig. 3 The 3 year survival Kaplan-Meier curve between the CAS and Conventional group. No significant difference $(p=0.304)$ in survival was found 
the conventional group. However, we consider this difference not of clinical significance. We did not observe any difference in the mean postoperative SSA between the two treatment groups, nor in the number of hips with a postoperative difference in SSA of $\geq 3, \geq 7$ or $\geq 10$ degrees from the preplanned SSA. These results show that CAS did not result in an increased accuracy in placement of the femoral component. In contrast to our results, Stiehler et al., did show a significant improvement in placement of the femoral component with the use of CAS. Fewer femoral components were positioned in $\geq 5$ degrees absolute deviation compared to preplanning in the CAS group [19]. In another, retrospective study, they showed a more accurate placement of the femoral component and less deviations from the planned SSA was accomplished with the use of CAS [37].

The impact of CAS on several aspects of patients' functioning (HHS, HOOS and VAS) was evaluated during a one-year follow-up period. Although the patients differed in their level of activities of daily living and sport at baseline, these differences were not clinically relevant. We did observe an overall improvement of patients' functioning over time, but this was similar for the two treatment groups. All results are consistent with previous studies $[9,19,37]$.

Our study has several limitations. Unfortunately due to recall of the ASR system, the study was prematurely terminated, resulting in a lower number of patients than needed, possibly hampering our statistical analysis. Selective protocol deviations due to incidentally unavailability of the CAS system in certain surgeries possibly influenced our study outcome. In this case, per protocol analysis would provide a better estimate of the effects of this method. Lastly, our longitudinal analysis of PROs was hampered by missing data. As missing data occurred due to termination of the study, selective bias will be limited, as patients who completed the data are representative of the study population.

\section{Conclusions}

Despite the limitations and recall of the ASR prosthesis we feel obligated to present our results. As orthopedic surgeons we have to strive to perform better and always search for optimization of a procedure. In our study, we show no added value for the use of imageless CAS in placement of the femoral component. In addition, CAS also did not improve any of the Patient-Centered Outcomes after one year follow up. Therefore we do not expect that CAS will result in long-term event-free survival, but this remains to be determined in long-term follow up.

\section{Abbreviations}

AP: Anteroposterior: ARMD: Adverse Reaction to Metal Debris; ASR: Articular Surface Replacement; BMI: Body Mass Index; CAS: Computer Assisted Surgery;
CCD: Centrum-Collum-Diaphysis; HHS: Harris Hip Score; HOOS: Hip disability and Osteoarthritis Outcome Scale; HRA: Hip Resurfacing Arthroplasty; ICC: Intra-Class Correlation; MoM: Metal-on-Metal; PROMs: Patient Related Outcome Measures; PROs: Patient Reported Outcomes; RCT: Randomized Controlled Trial; SSA: Stem Shaft Angle; VAS: Visual Analogue Scale

\section{Acknowledgement's}

The authors thank Ante Prkic for his practical help during the trial period.

\section{Authors' contributions}

M.C.K.: Main author of concept and design, performed radiographic measurements and statistical analyses. M.R.: Author made substantial contribution to concept and design, statistical analyses and to the writing of the manuscript. E.M.E.: Author made substantial contribution to concept and design, statistical analyses and radiographic measurements. J.H.W.: Author made substantial contribution to statistical analyses and to the writing of the manuscript. H.W.J.K.: Orthopedic surgeon performed the operations and made substantial contribution to the writing and revision of the manuscript. S.B.K.: Orthopedic surgeon performed the operations and made substantial contribution to the writing and revision of the manuscript. I.J.: Orthopedic surgeon performed the operations and made substantial contribution to the writing and revision of the manuscript. F.C.B.: Orthopedic surgeon performed the operations and made substantial contribution to the writing and revision of the manuscript. J.A.N.V.: Author made substantial contribution to concept and design and to the writing and revision of the manuscript. P.K.B.: Orthopedic surgeon performed the operations and made substantial contribution to the writing and revision of the manuscript. All above mentioned authors have red and approved the manuscript.

\section{Funding}

All institutions had received, during the study period, funding from: DePuy International Ltd., Leeds, UK. The funding was used for materials and building an online database during the trial period. The funding body had no influence during analysis, interpretation of the data and writing of this article. No author or any member of his or her family has had funding or commercial associations that might pose a conflict of interest in connection with the submitted article.

\section{Availability of data and materials}

All data are stored at different secured servers in the Erasmus University Medical Center to ensure the safety and de-identification. To access the data a written request can be send to the Erasmus University Medical Center, Department of Orthopedics, PO Box 2040, 3000 CA Rotterdam, the Netherlands.

Ethics approval and consent to participate

A METC approval is attached in the documents. All patients signed consent to participate.

Consent for publication

All patients signed informed consent for the use of the data for publication.

\section{Competing interests}

The authors declare that they have no competing interests.

\section{Author details}

'Department of Orthopedics, Erasmus University Medical Center, PO BOX 2040, 3000, CA, Rotterdam, The Netherlands. ' ${ }^{2}$ epartment of Orthopedics, Maxima Medical Center, Eindhoven, The Netherlands. ${ }^{3}$ Department of Orthopedics, Medical Center Haaglanden, Den Haag, The Netherlands. ${ }^{4}$ Department of Orthopedics, Admiraal de Ruyter Hospital, Goes, The Netherlands.

Received: 1 August 2019 Accepted: 7 October 2019

Published online: 25 October 2019

\section{References}

1. Daniel J, Pynsent PB, McMinn DJ. Metal-on-metal resurfacing of the hip in patients under the age of 55 years with osteoarthritis. J Bone Joint Surg Br. 2004;86(2):177-84 
2. Treacy RB, McBryde CW, Pynsent PB. Birmingham hip resurfacing arthroplasty. A minimum follow-up of five years. J Bone Joint Surg Br. 2005; 87(2):167-70.

3. Vale L, Wyness L, McCormack K, McKenzie L, Brazzelli M, Stearns SC. A systematic review of the effectiveness and cost-effectiveness of metal-onmetal hip resurfacing arthroplasty for treatment of hip disease. Health Technol Assess. 2002;6(15):1-109.

4. Hart AJ, Skinner JA, Henckel J, Sampson B, Gordon F. Insufficient acetabular version increases blood metal ion levels after metal-on-metal hip resurfacing. Clin Orthop Relat Res. 2011;469(9):2590-7.

5. Langton DJ, Jameson SS, Joyce TJ, Hallab NJ, Natu S, Nargol AV. Early failure of metal-on-metal bearings in hip resurfacing and large-diameter total hip replacement: a consequence of excess wear. J Bone Joint Surg Br. 2010; 92(1):38-46

6. Langton DJ, Joyce TJ, Jameson SS, Lord J, Van Orsouw M, Holland JP, Nargol AV, De Smet KA. Adverse reaction to metal debris following hip resurfacing: the influence of component type, orientation and volumetric wear. J Bone Joint Surg Br. 2011;93(2):164-71.

7. Pandit H, Glyn-Jones S, McLardy-Smith P, Gundle R, Whitwell D, Gibbons CL, Ostlere S, Athanasou N, Gill HS, Murray DW. Pseudotumours associated with metal-on-metal hip resurfacings. J Bone Joint Surg Br. 2008;90(7):847-51.

8. Matharu GS, Judge A, Murray DW, Pandit HG. Prevalence of and risk factors for hip resurfacing revision: a cohort study into the second decade after the operation. J Bone Joint Surg Am. 2016;98(17):1444-52.

9. Oak SR, Strnad GJ, O'Rourke C, Higuera CA, Spindler KP, Brooks PJ. Mid-term results and predictors of patient-reported outcomes of Birmingham hip resurfacing. J Arthroplast. 2017;32(1):110-8.

10. Daniel J, Pradhan C, Ziaee H, Pynsent PB, McMinn DJ. Results of Birmingham hip resurfacing at 12 to 15 years: a single-surgeon series. Bone Joint J. 2014; 96-B(10):1298-306.

11. Shimmin AJ, Back D. Femoral neck fractures following Birmingham hip resurfacing: a national review of 50 cases. J Bone Joint Surg Br. 2005;87(4): 463-4.

12. Beaule PE, Lee JL, Le Duff MJ, Amstutz HC, Ebramzadeh E. Orientation of the femoral component in surface arthroplasty of the hip. A biomechanical and clinical analysis. J Bone Joint Surg Am. 2004;86-A(9):2015-21.

13. Amstutz HC, Campbell PA, Le Duff MJ. Fracture of the neck of the femur after surface arthroplasty of the hip. J Bone Joint Surg Am. 2004;86-A(9): 1874-7

14. Amstutz HC, Beaule PE, Dorey FJ, Le Duff MJ, Campbell PA, Gruen TA Metal-on-metal hybrid surface arthroplasty: two to six-year follow-up study. J Bone Joint Surg Am. 2004;86-A(1):28-39.

15. Ulrich SD, Bonutti PM, Seyler TM, Marker DR, Jones LC, Mont MA. Outcomes-based evaluations supporting computer-assisted surgery and minimally invasive surgery for total hip arthroplasty. Expert Rev Med Devices. 2007;4(6):873-83.

16. Leenders T, Vandevelde D, Mahieu G, Nuyts R. Reduction in variability of acetabular cup abduction using computer assisted surgery: a prospective and randomized study. Comput Aided Surg. 2002;7(2):99-106.

17. Liu Z, Gao Y, Cai L. Imageless navigation versus traditional method in total hip arthroplasty: a meta-analysis. Int J Surg. 2015;21:122-7.

18. Stiehler M, Goronzy J, Kirschner S, Hartmann A, Schafer T, Gunther KP. Effect of surgical experience on imageless computer-assisted femoral component positioning in hip resurfacing--a preclinical study. Eur J Med Res. 2015;20:18.

19. Stiehler M, Goronzy J, Hartmann A, Krummenauer F, Gunther KP. The first SICOT Oral presentation award 2011: imageless computer-assisted femoral component positioning in hip resurfacing: a prospective randomised trial. Int Orthop. 2013;37(4):569-81.

20. Olsen M, Davis ET, Chiu M, Gamble P, Tumia N, Boyle RA, Schemitsch EH. Imageless computer navigation without pre-operative templating may lead to malpreparation of the femoral head in hip resurfacing. J Bone Joint Surg Br. 2009;91(10):1281-6.

21. Ganapathi M, Vendittoli PA, Lavigne M, Gunther KP. Femoral component positioning in hip resurfacing with and without navigation. Clin Orthop Relat Res. 2009;467(5):1341-7

22. Bailey C, Gul R, Falworth M, Zadow S, Oakeshott R. Component alignment in hip resurfacing using computer navigation. Clin Orthop Relat Res. 2009; 467(4):917-22.

23. de Groot IB, Reijman M, Terwee CB, Bierma-Zeinstra SM, Favejee M, Roos EM, Verhaar JA. Validation of the Dutch version of the hip disability and osteoarthritis outcome score. Osteoarthr Cartil. 2007;15(1):104-9.
24. Price DD, McGrath PA, Rafii A, Buckingham B. The validation of visual analogue scales as ratio scale measures for chronic and experimental pain. Pain. 1983;17(1):45-56.

25. Soderman $\mathrm{P}$, Malchau $\mathrm{H}$. Is the Harris hip score system useful to study the outcome of total hip replacement? Clin Orthop Relat Res. 2001;384:189-97.

26. Bland JM, Altman DG. Statistical methods for assessing agreement between two methods of clinical measurement. Lancet. 1986;1(8476):307-10.

27. Beaule PE, Campbell PA, Hoke R, Dorey F. Notching of the femoral neck during resurfacing arthroplasty of the hip: a vascular study. J Bone Joint Surg Br. 2006;88(1):35-9.

28. Beaule PE, Dorey FJ, Le Duff MJ, Gruen T, Amstutz HC. Risk factors affecting outcome of metal-on-metal surface arthroplasty of the hip. Clin Orthop Relat Res. 2004:418:87-93.

29. de Steiger RN, Hang JR, Miller LN, Graves SE, Davidson DC. Five-year results of the ASR XL Acetabular system and the ASR hip resurfacing system: an analysis from the Australian Orthopaedic Association National Joint Replacement Registry. J Bone Joint Surg Am. 2011;93(24):2287-93.

30. Jameson SS, Baker PN, Mason J, Porter ML, Deehan DJ, Reed MR. Independent predictors of revision following metal-on-metal hip resurfacing: a retrospective cohort study using National Joint Registry data. J Bone Joint Surg Br. 2012;94(6):746-54.

31. Olsen M, Schemitsch EH. Avoiding short-term femoral neck fracture with imageless computer navigation for hip resurfacing. Clin Orthop Relat Res. 2011:469(6):1621-6.

32. Romanowski JR, Swank ML. Imageless navigation in hip resurfacing: avoiding component malposition during the surgeon learning curve. J Bone Joint Surg Am. 2008;90(Suppl 3):65-70.

33. Seyler TM, Lai LP, Sprinkle DI, Ward WG, Jinnah RH. Does computerassisted surgery improve accuracy and decrease the learning curve in hip resurfacing? A radiographic analysis. J Bone Joint Surg Am. 2008; 90(Suppl 3):71-80.

34. Schnurr C, Nessler J, Meyer C, Schild HH, Koebke J, Konig DP. Is a valgus position of the femoral component in hip resurfacing protective against spontaneous fracture of the femoral neck?: a biomechanical study. J Bone Joint Surg Br. 2009;91(4):545-51.

35. Schnurr C, Michael JW, Eysel P, Konig DP. Imageless navigation of hip resurfacing arthroplasty increases the implant accuracy. Int Orthop. 2009; 33(2):365-72.

36. Hart R, Svab P, Filan P. Intraoperative navigation in hip surface arthroplasty: a radiographic comparative analysis study. Arch Orthop Trauma Surg. 2008; 128(4):429-34.

37. El Hachmi M, Penasse M. Our midterm results of the Birmingham hip resurfacing with and without navigation. J Arthroplast. 2014;29(4):808-12.

\section{Publisher's Note}

Springer Nature remains neutral with regard to jurisdictional claims in published maps and institutional affiliations.

Ready to submit your research? Choose BMC and benefit from:

- fast, convenient online submission

- thorough peer review by experienced researchers in your field

- rapid publication on acceptance

- support for research data, including large and complex data types

- gold Open Access which fosters wider collaboration and increased citations

- maximum visibility for your research: over $100 \mathrm{M}$ website views per year

At BMC, research is always in progress.

Learn more biomedcentral.com/submission 